\title{
VIDAS DE PROFESSORAS DE ESCOLAS RURAIS: MEMÓRIAS DA MANHÃ, TARDE E NOITE
}

\author{
Neurilene Martins Ribeiro* \\ Elizeu Clementino de Souza**
}

Resumo: Neste artigo tencionamos compartilhar considerações sobre redes de relações constitutivas da aprendizagem da docência, a partir da tematização das relações entre docência e gênero, bem como questões concernentes aos modos como utilizamos às narrativas de docentes de escolas rurais sobre tempos, movimentos e deslocamentos para aprender/ser professora em escolas rurais, em articulação com dimensões da pesquisa (auto)biográfica. O texto desdobra como ação da pesquisa 'Ruralidades diversas - Diversas ruralidades: sujeitos, instituições e práticas educativas em escolas do campo Bahia-Brasil', ao enfocar recortes do subprojeto 'Histórias de professoras de Língua Portuguesa: dilemas e saberes da profissão docente nos ciclos iniciais da carreira', cujo corpus compõe-se de vozes de dezesseis mulheres sobre vidas de professoras nos anos iniciais da carreira do Território da Chapada Diamantina. Tomamos como fontes para a pesquisa carta, grupo focal, entrevista narrativa e relatório sobre a prática docente, na perspectiva de sistematizar questões de ensino e de formação sobre o trabalho docente em escolas rurais, visto que para a escola na contemporaneidade e a vida dos educadores, entre os discursos oficias e as itinerâncias das escolas, há distâncias, clivagens e paradoxos invisibilizados nos discursos oficiais.

Palavras-chave: Trabalho docente. Escolas rurais. Pesquisa (auto)biográfica. Professoras de Língua Portuguesa. 


\section{Teacher's life for rural schools: memories of the morning, afternoon and evening}

Abstract: In this article we intend to share considerations networks constitutive relations of learning of teaching, from the thematization of relations between educators and gender, as well as issues pertaining to the ways narratives we use to teachers of rural schools on time, to learn movements and displacements/be teacher in rural schools, in conjunction with dimensions of research (auto) biographical. The text unfolds as action research 'Ruralities diverse - Several ruralities: individuals, institutions and educational practices in schools field Bahia-Brazil', by focusing clippings subproject 'Stories of Portuguese Language teachers: dilemmas and knowledge of the teaching profession in cycles early career', whose corpus consists of sixteen voices on the lives of women teachers in the early years of the career of the Territory of Chapada Diamantina. We as sources for research letter, focus group interview and narrative report on the teaching practice, from the perspective of systematic issues of education and training on teaching in rural schools, since for school and life in contemporary educators, between the official discourse and the itinerancies schools, there are distances, cleavages, and paradoxes invisible in official speeches.

Keywords: Teacher work. Rural schools. Search (auto)biographical. Teaching Portuguese Language. 


\section{Manhã, tarde e noite: questões sobre docência e formação em escolas rurais}

Ser professora na América Latina ${ }^{1}$, no Nordeste brasileiro, na Chapada Diamantina, parece ser mesmo uma saga. Uma saga representada, muitas vezes, por jovens, filhos de famílias simples, rurais, que, no século XX, não chegaram a ingressar na escola e, quando o fizeram, foi atravessando rios e distâncias a pé, ou, com sorte, sendo transportados em veículos sucateados para chegar à escola mais próxima. Egressas de tais famílias são, atualmente, na região da Chapada Diamantina, as professoras de Língua Portuguesa, aquelas que adentram as instituições escolares com a responsabilidade de fazer a "Educação de Qualidade", meta preconizada pelos Órgãos Oficiais e pelas políticas públicas federais e locais, de Norte a Sul do Brasil. Entre as metas para a escola na contemporaneidade e as condições de vida e de trabalho dos educadores, entre os discursos oficias e as itinerâncias das escolas, dos alunos e dos professores, há distâncias, clivagens, lacunas, fossos, paradoxos, que pouco, ou nunca, aparecem nos discursos oficiais, sustentados pelas narrativas hegemônicas, lugar da voz dos grupos economicamente e socialmente privilegiados, dos quais os professores não fazem parte. Quando inscritos, todavia, em tais discursos, aparecem como o alvo mais fácil de abater, como afirma Nóvoa (2003), no âmbito de dispositivos ideológicos neoliberais de controle e de desvalorização da profissão docente, questão também apontada nos estudos de Dias e Lopes (2003), ao analisarem o conceito de competência na reforma curricular de formação de professores, na década de 90 do século XX.

No cenário das histórias de vida, como metodologia de pesquisa e de formação, tomamos a ideia de que o trabalho com as 
narrativas de professoras pode favorecer a construção de uma contramemória sobre a profissão docente ${ }^{2}$. Ouvir as histórias de vida e de profissão de mulheres professoras da Chapada Diamantina permitiu-nos adentrar em "outros mundos “[...] e desse lado é que se pode ver como certas coisas são feitas: recortes, parafusos, encaixes [...]" (MEIRELES, 1983, p. 8-9), o que nos parece fundamental para a construção de uma perspectiva singular e necessária sobre a vida dos professores e sua formação, quando trabalham, e sobre a escola como espaço da construção da vida e da profissão. Ampliamos essa perspectiva no diálogo com Warschauer (2001), que recoloca as narrativas dos professores no contexto das lutas pela profissionalização e construção da identidade docente, ao afirmar que:

Construir essa contra-memória é forjar a identidade da profissão pela construção de sua história, pois é preciso que haja uma história para que uma comunidade se reconheça. Ao mesmo tempo ao revelar como se faz essa profissão, contribui para que venha a ter, mesmo que num futuro distante, um reconhecimento social que falta à profissão e torna a tarefa mais árdua aos professores, imersos no descrédito e demérito. (WARSCHAUER, 2001, p. 192).

Pensamos que tal demérito e descrédito, assinalados pela autora, ao revelarem faces de uma profissão em crise, devem provocar um debate mais amplo que inclua a reflexão sobre a formação docente no contexto da crise pela qual passa a instituição escolar. Se esse é um tema quase redundante nos debates acadêmicos, não o é a abordagem realizada por Miguel Arroyo (2004), ao tematizar a decadência da escola sob o prisma das transformações nas representações sobre infância e a adolescência, e a relação dessas 
mudanças com a crise de identidade docente. O autor afirma que os professores - que somos - foram forjados a partir de um ideário de infância e de adolescência que não corresponde mais às trajetórias diversamente problemáticas dos alunos nossos "de cada dia", o que coloca em xeque imagens clássicas da profissão docente ${ }^{3}$, entrecruzamento tematizado no livro Imagens quebradas trajetórias e tempos de alunos e mestres. Se o descompasso entre as imagens de alunos e de professores, construídas historicamente, e as feições desses sujeitos no cotidiano social e escolar parecem invisíveis nos discursos oficias, o mesmo não se aplica quando a mirada é feita pelo lado de dentro da escola, pelo prisma de um dos atores sociais que nela vivem: as professoras de Língua Portuguesa.

Neste sentido, ao tomamos as narrativas das professoras sobre suas trajetórias profissionais, como objeto da pesquisa ${ }^{4}$, reconhecendo-as como produtoras e portadoras de saberes ${ }^{5}$, foi possível apreender tempos e deslocamentos da aprendizagem da docência nos anos iniciais da carreira. Tal dinâmica é marcada por movimentos contraditórios e rearranjos da sociedade na contemporaneidade, nos quais está inscrita a instituição escolar, cujas imagens quebradas denunciam sua derrocada, ao tempo em que anunciam a emergência de novas ordens e estruturas educacionais. Ecoam forte as vozes das professoras ao sublinharem a necessidade da escola se reconstruir como redes colaborativas de aprendizagem, $\mathrm{o}$ que não se dá sem a garantia das horas para o trabalho coletivo na escola, e sem dispositivos de partilha e acompanhamento do trabalho pedagógico, condições necessárias para práticas colaborativas, construção de processos formativos e (auto)formativos e, também, a emergência do sujeito social que aprende, como nomeia Pineau (1999), no contexto de uma escola aprendente, que 
fomenta a formação de professores que pensam, refletem e reinventam suas práticas.

As professoras denunciam, desse modo, o vazio da formação na instituição escolar, ao dizerem que os tempos de encontro e de partilha entre professores acabam configurando-se em momentos descontinuados e assistemáticos, forjados nas brechas do cotidiano escolar.

O corpus da pesquisa sugere que a ideia de que ninguém é professor sozinho, como afirma Nóvoa (2003), parece carecer de melhor realização nas escolas de $5^{0}$ ao $9^{0}$ anos da região pesquisada. A recomendação feita por Nono e Mizukami (2006), de que haja algum elo entre a formação inicial e a formação continuada, para melhor aportar a iniciação na profissão docente, é desafiada duplamente sob a ótica das narrativas das professoras. Apreendemos o entrecruzamento de duas lacunas: uma promovida pela ausência da formação acadêmica, pois, via de regra, a atuação de professores não licenciados figura como um traço da docência na educação básica, na região da Chapada Diamantina, perfil de $100 \%$ das professoras colaboradoras ${ }^{7}$; e a outra promovida pelo vazio das práticas de formação continuada na escola, que, de espaço privilegiado para o desenvolvimento profissional de professores, vê-se transformada em lugar de rotinização e fragmentação do trabalho docente, acentuando, sobremaneira, os desafios colocados ao professor iniciante. $\mathrm{O}$ excerto da narrativa da professora Luciana revela o mal-estar que tende a caracterizar a fase inicial da carreira, quando afirma que:

Acho que na carreira a gente vai ter desafio sempre. Só que no início é mais. Vem a insegurança, o medo de tá, as vezes, não temos acompanhamento, sem saber se aquilo 
que a gente tá passando, tá indo bem ou não. Acho que, nesse início, o medo é mais e também a insegurança. Que quando eu comecei mesmo, foi assim, você vai ficar com essa disciplina e o livro tá aí. Era apenas um livro e eu. Tinha que tá buscando fora, porque, se eu não tivesse buscando ajuda com outros colegas, eu iria estar sozinha, isolada. Então, é esse mesmo. Eu acho que o pior desafio é o início mesmo. Você tá sozinho e não ter alguém pra tá lhe auxiliando. Você tem que mesmo buscar (Luciana).

Saber que as experiências iniciais da docência podem figurar como referências para a vida profissional, ao longo de toda a carreira, influenciando os modos de ser e estar na profissão, como afirma Nóvoa (2006), não é suficiente para que o apoio ao professor iniciante configure-se como política de formação continuada e em conteúdo da formação de formadores. Ao pensar e propor a formação continuada de professores, ancorada no tripé desenvolvimento pessoal, profissional e institucional, o discurso de Nóvoa (1997) entrecruza-se com as narrativas de Aparecida e de Luciana pelo viés da lucidez e da busca pelo atendimento de um conjunto de condições que precisa ser garantido para o trabalho docente, desde o início da carreira.

Neste artigo, tencionamos compartilhar considerações sobre as redes de relações constitutivas da aprendizagem da docência, a partir da tematização sobre docência e gênero; e a análise dos tempos e movimentos da vida das professoras, face à leitura interpretativa do corpus da pesquisa, como se fora uma colcha de retalhos. Nele, as metanarrativas são tragadas pela riqueza das vozes de dezesseis mulheres a se contar, a nos contar, sobre como se tornaram professoras, quais saberes as constituem e sobre os modos peculiares de ser professora nos anos iniciais da carreira, em contextos insólitos. 
Trazem, assim, traços da história da educação nordestina, rural, sob o prisma feminino, cuja atuação marca, sobretudo, a docência em Língua Portuguesa, na região da Chapada Diamantina.

\section{Docência e gênero: tecendo redes de formação}

O Magistério foi a opção de formação de 15 das 16 professoras pesquisadas, o que indica que muitas delas viveram essa formação sob os ditames da Lei 5692/71, com orientação eminentemente tecnicista, experiência análoga a minha como normalista na década de 1980, em escola estadual, no interior da Bahia. As narrativas das professoras de Língua Portuguesa são emblemáticas dos processos de construção da identidade da mulher professora, inscritos na história da profissão docente marcada, por sua vez, pela feminização da profissão e pelo progressivo desprestígio da mesma, a partir da década de 50 do século XX, no âmbito da qual se disseminou uma imagem negativa da docência, como apontam os estudos de Almeida (1998). Os relatos sobre o ingresso no Magistério revelam trajetórias de jovens mulheres que, ao viverem no interior do estado, tiveram no Magistério quase a única oportunidade para progredir nos estudos e, ao mesmo tempo, galgar uma formação profissional, na escuta do velho conselho, ainda vigente, de que "professora em qualquer lugar tem trabalho".

O mito da vocação e do dom para ser professora é confrontado nos relatos das docentes, uma vez que, de modo geral, apresentam como fios iniciais que as levaram ao Magistério, eventos que vinculam com o acaso e a sorte, de modo que a identificação com a profissão se deu tempos depois, no exercício da docência. Locali- 
zamos, no relato de Pereira $(2003)^{8}$, um ponto de vista semelhante ao das professoras, ao relatar a sua própria trajetória profissional e a entrada no magistério. Distanciando-se da ideia do magistério como dom, conta como trilhou o percurso de secretária experiente à professora engajada, ao dizer que “[...] na verdade não escolhi minha profissão. Vim para o magistério de forma mais ou menos inesperada." (PEREIRA, 2003, p. 157). Esta fala faz coro com as narrativas das professoras Edna e Maiara sobre os encontros inusitados, ou mesmo acidentais, que viveram com o magistério. A primeira confessa que começou a dar aulas sem grandes expectativas, e a segunda compartilha o modo inusitado de ingresso na profissão, quando o convite para atuar como secretária deu lugar a uma sala de aula. O desejo permanente de ser professora, no entanto, é trazido nas narrativas das professoras Aparecida e Luana, que encontram nas brincadeiras infantis as primeiras representações da profissão docente: nelas, Aparecida e Luana queriam ser sempre as professoras.

Encontramos nas ideias de Jesus ${ }^{9}$ elementos significativos para melhor compreender a manipulação ideológica subjacente à representação do magistério vinculada à ideia de vocação e dom, ao afirmar que:

Desmistificar o discurso de que para ser professora é preciso nascer com um 'dom', 'ter vocação' é um importante ponto de partida para percebermos o quão complexa é essa profissão, os caminhos que envolvem a opção inicial ou não pelo magistério e a identificação com a profissão. Tais caminhos vêm imbricados de questões mais profundas que envolvem a feminilidade, numa visão não reduzida à dicotomia masculino/feminino; a garantia da ocupação/ ampliação do espaço público, bem como da possibilidade da política de interferência neste espaço; a idéia religiosa 
e romântica de fazer o bem comum; a idealização e sublimação de uma profissão para mulheres. (JESUS, 2003, p. 24-25).

Concordamos com Jesus ao abordar a construção identitária como território de subjetividades e ideologias, entendida por Nóvoa (2000) como palco de lutas e conflitos, e por Lawn (2000) na perspectiva de fabricações ideológicas do Estado. Nas palavras das professoras, evidenciaram-se as ambiguidades na relação que estabelecem com a carreira, do ponto de vista existencial e profissional: elas têm paixão pela profissão, mas, às vezes, pensam em desistir e dizem da necessidade de partilha e formação, ao mesmo tempo que reclamam de uma profissão que é trabalhosa e demanda muitos tempos e espaços da vida. Explicitam, ainda, uma preocupação evidente pelos alunos que não avançam nas aprendizagens, mas, ao mesmo tempo, ao serem dilematizadas por eles, por vezes, parecem preferir os alunos bonzinhos e pacíficos. Intentam, também, formar leitores, mas nem sempre priorizam rituais pessoais de leitura, entre outros aspectos, que desafiam as vidas "de professora".

Evidenciamos que a construção da identidade docente se dá em um tempo longo da carreira, não estando circunscrita à formação profissional, é interessante retomar as trilhas profissionais das professoras colaboradoras para perceber como professoras primárias ascenderam ao lugar de professoras de Língua Portuguesa, no segmento de $5^{0}$ ao $9^{0}$ anos. De modo geral, a inserção neste segmento foi precedida pela docência no segmento de $1^{\mathrm{a}}$ a $4^{\mathrm{a}}$ séries, ou mesmo pela docência em outra disciplina, como se pode ver na trajetória das professoras Aparecida, Júlia e Cleide, que lecionavam Matemática e Geografia, antes de Língua Portu- 
guesa. A exceção fica por conta da experiência da professora Maiara que vive o primeiro ano da carreira como professora de Língua Portuguesa.

Para chegar às salas de aula como professoras de Língua Portuguesa, este grupo de mulheres parece ter seguido caminhos muito semelhantes. Convidamo-las para nos contar parte dessa saga que, curiosamente, apontam para algumas condições singulares: ingressar no grupo de professores do $5^{0}$ ao $9^{0}$ anos significa ter abertura para assumir qualquer uma das disciplinas do currículo desse segmento; é possível que o professor tenha que lecionar mais de uma disciplina simultaneamente ${ }^{10}$; a cada ano a distribuição das disciplinas entre os professores pode ser alterada. Os excertos das narrativas das professoras Aparecida e Edna trazem traços dessas histórias.

[...] Eu leciono há dois anos na escola do Mucambo, antes lecionava Matemática e caí de pára-quedas para lecionar Língua Portuguesa.

Como foi isso? Eu sou professora há treze anos, mas de outro município, de Ibipitanga e aí eu fiz o concurso e aí quando cheguei em Mucambo só sobrou Língua Portuguesa. Aí eu levei até um susto porque eu nunca gostei de Português, não era muito boa em Português. (Aparecida).

Como eu sempre, na minha fase de estudante, eu me destaquei nessa área, eu resolvi me tornar professora de Língua. Então, antes disso, eu trabalhei, no que, por falta de opção, no que sobrou pra mim, mas quando pude optar, que foi quando eu fiz o concurso, entrei pra rede municipal, eu a escolhi, a disciplina. (Edna).

No conjunto das narrativas, foi possível observar que a identificação com a disciplina Língua Portuguesa, ou mesmo o bom 
desempenho na disciplina na trajetória escolar, foram fatores que, por vezes, definiram o encontro dessas mulheres com as aulas de Português. A Licenciatura em Letras, como critério para selecionar professores de Língua Portuguesa, de acordo ao que determina a Lei de Diretrizes e Bases para a Educação Nacional, sobre a formação de docentes para atuar na educação básica, parece ser secundarizada nesse contexto, mesmo diante de professoras que já estão cursando a licenciatura. A professora Maiara, estudante de Letras, conta que, inicialmente, o convite foi para ela atuar como secretária, não como professora de Língua Portuguesa. Ao dizer que, por sorte, identificou-se com a disciplina, oferece pistas para pensar que essa prática parece naturalizar-se do ponto de vista dos próprios professores, o que se evidencia também no excerto da professora Aparecida, ao contar a sua itinerância, de professora de Matemática à professora de Língua Portuguesa.

Nota-se que o vazio da formação acadêmica é diluído na seleção e enturmação dos professores, uma vez que os docentes da região estão longe de atender ao perfil determinado pela Lei que preconiza a atuação de professores licenciados ${ }^{11}$. Tais dados sublinham, mais uma vez, o caráter excludente das políticas públicas de formação inicial para as regiões consideradas pelo Estado como periféricas e, novamente, paradoxos emergem da pouca congruência entre as Leis da educação e a vida do educador. Encontramos, nos estudos de Fanfani (2007), um panorama da formação profissional na América Latina, quando realiza um estudo comparativo sobre a condição da docência na Argentina, Peru, Brasil e Uruguai. O autor aponta que, no Brasil, 4,6\% das professoras entrevistadas não possuem título para exercer a docência, frente a $0,1 \%$, identificado na Argentina, 3,4\% no Peru e $11 \%$ no Uruguai. Por sua vez, Marques (2006, p. 7), ao abordar a questão 
da formação dos professores dos meios populares, afirma que " [...] na região Nordeste, apenas $27,7 \%$ dos professores da educação básica têm nível superior, contra $67 \%$ que têm somente o nível médio [...]." Diante de tal quadro, o ingresso, a permanência e o sucesso dos professores de classes populares nas universidades precisam constituir-se em temática de maior interesse da sociedade como um todo, mas, principalmente, dos grupos corporativos, das políticas públicas de formação e das universidades.

Desafiando a Lei, as professoras colaboradoras da pesquisa, primeiro assumiram as classes de $5^{\mathrm{a}}$ a $8^{\mathrm{a}}$ séries, depois ingressaram no ensino superior nos cursos de Pedagogia, Turismo, Normal Superior e Letras. Por outro lado, identifico que a realização de concursos públicos pode ter se constituído em um momento-charneira para a vida profissional dessas mulheres, uma vez que $94 \%$ das professoras são concursadas em seus municípios. Neste sentido, compartilhamos, como Almeida (1998), que o magistério representa, de fato, na história da profissionalização feminina, um marco ao mediar a entrada da mulher no universo do trabalho assalariado, não sem tensões e conflitos, mas, certamente, arrastando vitórias substantivas. Ao considerar que, até o século XIX, a leitura e a escrita eram para nós mulheres objetos proibidos, a ascensão ao lugar de professora pode ser reconhecido como uma revolução na história da mulher. Localizamos, nos estudos de Guedes-Pinto e Fontana (2004), sobre leitura e docência, contribuições para pensar a relação entre gênero e docência em Língua Portuguesa, ao afirmarem que:

Conforme Ribeiro (2000, p. 79), 'tanto as mulheres brancas, ricas ou empobrecidas, como as negras escravas e as indígenas não tinham acesso à arte de ler e escrever'. $\mathrm{O}$ 
acesso à leitura, que algumas chegavam a ter, era garantido pelo aprendizado na família, durante a infância e destinado aos livros de reza. (GUEDES-PINTO; FONTANA, 2004, p. 167).

Como as mulheres professoras da Chapada Diamantina não são "ricas", condição na qual se inscreve a minoria das docentes brasileiras, há que se pensar como essa herança, ampliada pela categoria classe social, está imiscuída na vida das professoras, quando elas são convocadas a formar leitores e escritores. Tomamos os estudos de Fanfani (2007) para pensar essa questão em tempos atuais de crises e direitos: “[...] a excepción de Brasil, la gran mayoría de los docentes nacieron y se desarrollaron em hogares com capital educativo médio y alto; em esse país, por el contrario, la mayoria de los docentes son hijos de padres com bajo grado de escolaridad (6 años o menos) [...]." (FANFANI, 2007, p. 48). Essa é uma dimensão que redefine as questões da docência no Brasil, agravadas na região onde vivemos, o Nordeste brasileiro, e que está implicada nos resultados dessa pesquisa.

Escutar as professoras da zona rural da região da Chapada Diamantina é uma chance, então, para adentrar um pouco mais na vida de professores, nas suas rotinas, tempos e contratempos.

\section{Tempos e movimentos da profissão docente}

Começamos essa seção por apresentar-lhes o fragmento de uma vida, a vida da professora Cleide.

Cleide é uma jovem professora que ingressou, por meio de concurso público, na rede municipal de Ibitiara, no ano de 2004, 
um ano após ter concluído o curso de Magistério. Moradora da região, cursou o Magistério na Zona Rural, no distrito de Mucambo, e, por um tempo, chegou a morar em São Paulo. Com o evento do casamento, passou a residir em Caldeirão, um outro povoado de Ibitiara, onde, com o marido que é professor de Matemática, passou a atuar na escola de $5^{\mathrm{a}}$ a $8^{\mathrm{a}}$ séries, como professora de Língua Portuguesa. Nesse lugar tornou-se mãe.

Ela é uma mulher bonita, de voz doce, mas de semblante carregado de preocupação e, por vezes, de tristeza e inquietação, quando fala da vida da professora que estuda e trabalha, é mãe e esposa. Com um contrato de trabalho de 40 horas semanais, atuando um turno no primário e outro no colégio - modo corriqueiro como se referem aos segmentos de $1^{\mathrm{a}}$ a $4^{\mathrm{a}}$ séries e $5^{\mathrm{a}}$ a $8^{\mathrm{a}}$ séries do ensino fundamental, respectivamente -, a professora vive dilemas profissionais e existenciais que emergem principalmente da falta de fronteiras entre a vida profissional e a vida privada. $\mathrm{O}$ excerto da narrativa de Cleide é revelador desse campo de tensão.

Nós não trabalhamos quarenta horas, nós trabalhamos sessenta. Ninguém vai pra sala de aula sem preparar em casa. No momento que você tá com a família, tá com seu filho, tá corrigindo atividade, você tá preparando. No dia que não dá tempo de preparar tudo a noite, eu levanto cedinho pra tentar, né, terminar ali... seus planos, suas atividades. Então, você trabalha muito mais. Eu acharia que deveria, na minha visão, se você tem mais horas... vinte... deveria ser pra você planejar. Por que domingo, domingo não é dia de você descansar? Domingo você tem que planejar pra segunda! Tanto pra o colégio quanto pra o primário... Quem tem quarenta horas, né,. Se você tivesse pelo menos a sexta pra planejar, um dia na semana, você já planejava a semana toda. Eu acredito que seria um pouco melhor. Porque a gente precisa descansar também, tanto a mente quanto o corpo e tudo. Dar um tempo pra família... 
Estamos a abrir mão da família. Muitas vezes as mulheres não têm filhos por causa do trabalho, e depois não dá tempo de cuidar. Eu, se tivesse mais tempo, queria mais um, mas... do jeito que tá o tempo, você acaba abandonando. Ou você fica com complexo ou não tem como dividir. Você acaba abandonando mais ainda, sempre sobra pra o pessoal, pra família, pro descanso. (Cleide).

Ao retomarmos essa fala, somos flagrados pela lembrança da imagem da professora ao si dizer como mulher trabalhadora, cujo rosto e corpo, com emoção incontida, diziam das ambiguidades, paradoxos e desafios da profissão, que parecem torná-la, por vezes, desumana do ponto de vista da carga de trabalho, com seus rituais de planejamento e correção de provas, por exemplo, como assinala a professora. Reconhecemos, nesse discurso, coragem e lucidez necessárias para dar algum enfrentamento ao forte, antigo e atual discurso que relaciona a imagem da professora à resignação, abnegação, às ações caritativas de muitos sacrifícios e poucos direitos. Parece que essa questão transcende a vida da professora Cleide, quando a identifico no discurso nacional vigente, em debates recentes sobre a proposta encaminhada pelo então presidente da República, Luiz Inácio Lula da Silva, que propõe a ampliação da carga horária do professor para os trabalhos extra-classe. A legitimação do trabalho do professor na sua vida privada favorece a idéia de que ele trabalha pouco, como reafirma os estudos de Vasconcelos (2003), ao denunciá-lo como um trabalho invisível, mas objeto de cobranças. Nesse âmbito, identificamos novas manobras em favor da proletarização da docência, que arrasta de imediato a naturalização da política de baixos salários, temática debatida, todavia mal resolvida, no cenário brasileiro. Os dados da pesquisa sugerem que, não obstante a relevância das questões salariais ${ }^{12}$ na 
profissionalização docente, os conflitos relativos às condições de trabalho se sobrepõem àqueles concernentes à política salarial.

Ao inscrever o fragmento da narrativa da professora Cleide no conjunto do seu relato, identificamos, entretanto, que esse sentimento de peso máximo que a profissão lhe gera é ampliado pela ausência de espaços sistemáticos para planejamento coletivo e para a formação continuada na sua rotina profissional. Cleide leciona em um anexo da escola da sede, localizado na zona rural, que funciona sem diretor escolar, sem coordenador pedagógico e sem biblioteca, perfil apresentado por muitas escolas na região Nordeste, quando assumem a manutenção de anexos como alternativas provisórias e precárias para o atendimento das comunidades rurais ${ }^{13}$.

Penso que viver a docência em condições precárias, progressivamente, poderá perpetuar o mal-estar ${ }^{14}$ a que pude testemunhar em algumas narrativas, temática debatida nos estudos de Zaragoza (1999) e Lopes (2001), os quais discutem os fatores que criam esses estados de desconforto na vida do professor. Zaragoza (1999) apresenta, como fatores principais desse desconforto, problemas com os recursos materiais e com as condições de trabalho, além da violência nas instituições escolares, e do esgotamento docente face à acumulação de exigências sobre o professor. Lopes (2001), por sua vez, aborda essa problemática tomando como campos de tensão o contexto socioeducativo, as motivações pessoais, a formação inicial e o contexto escolar. Para além das diferentes categorizações cunhadas pelos autores, os resultados de tais estudos parecem úteis para sublinhar a proposta de Nóvoa (1997), de que a profissão docente precisa ser pensada à escala do desenvolvimento da vida do professor, da profissão e da escola, princípios também apontados nas narrativas das professoras de Língua Portuguesa. 
Finalmente, para dar conta de falar das professoras da manhã, tarde e noite, destacamos em um último traço ${ }^{15}$ marcante no perfil das professoras colaboradoras: todas são professoras que, enquanto produzem a vida e a profissão, estudam. Neste sentido, às largas jornadas de trabalho são somados os tempos e espaços para os compromissos de estudantes de graduação. Das 16 mulheres, nove cursam Letras - quatro na UNEB, três na FTC, uma na ULBRA e uma na UNOPAR -, seis cursam Pedagogia e uma Turismo. As professoras podem ser organizadas em agrupamentos distintos: as que cursam graduação presencial e semipresencial; as que cursam Letras e as que cursam outras licenciaturas - Turismo e Pedagogia; e, finalmente, as que cursam Letras em regime semipresencial e aquelas que cursam Letras em regime presencial.

Considerando essas especificidades, é possível antecipar os movimentos e deslocamentos das professoras para o estudo nos finais de semana, quando participam dos encontros de tutoria típicos dos cursos semipresenciais, ou o deslocamento dia a dia para frequentar o curso noturno na cidade vizinha ${ }^{16}$. Sá (2006), ao acompanhar percursos de professores de classes populares que estudam em Salvador, chama a atenção para o campo de tensão existencial e intelectual que emerge, quando se entrecruzam os tempos da formação inicial com os tempos do exercício da docência:

Ao assumirem a condição de professoras que estudam, assumem também a sobrecarga dos longos deslocamentos, das jornadas de trabalho ampliadas, das ausências na convivência familiar e, principalmente, do esforço intelectual para sistematizar um conhecimento novo. (SÁ, 2006, p. 15).

É doce fazer dialogar Sá (2006) e a professora Júlia, no excerto da narrativa, para sublinhar a força e o empenho das mulheres 
professoras da região da Chapada Diamantina, quando resolvem tomar nas mãos a própria vida, reinventando espaços e tempos nos quais também cabe o prazer de ser o que é:

É até engraçado essa coisa de faculdade. Puxa, acho que vai me fazer tanta falta! Que às vezes você acha cansativo você trabalhar a semana e no sábado... vim pra aqui fazer a faculdade. Às vezes é tanta experiência que um passa pro outro, um colega passa pro outro. '- Olha, eu li isso em tal livro, em tal autor'. (Júlia).

Por outro lado, é recorrente nas narrativas das professoras a referência ao trabalho que realizam em um "não lugar", nas altas horas da noite. O depoimento da professora Maiara traz o tom da vida dessas professoras estudantes: “[...] porque eu moro em Seabra. Aí trabalho em Palmeiras e tenho que vir pra faculdade. Então é a questão: trabalho, faculdade, mas tô levando." Pensamos que essa deva ser uma equação de difícil resolução: do ponto de vista da formação continuada, como engendrar dispositivos de formação que incluam as professoras como são, como estão - em estado permanente de deslocamentos zona rural/sede, zona rural/cidades vizinhas - para estudar, e com desafios acadêmicos e profissionais para dar conta.

\section{Alguns fios: a vida como processo formativo}

A discussão em torno da fertilidade das histórias de vida como metodologia da formação inspira-nos refletir sobre os lugares de aprendizagem da docência, uma vez que o pressuposto é de que a aprendizagem docente se dá à escala da vida, o que obviamente in- 
clui os espaços formais e os tempos sequenciados de formação, mas certamente transcende-os. Pensamos que trocar a lógica do ensino pela lógica da aprendizagem constitui-se, a despeito do grande desafio, um caminho possível para a formação de professores na contemporaneidade. Neste sentido, quaisquer que sejam os dispositivos de formação engendrados na aposta da fertilidade desse caminho, não se pode prescindir da ideia de que o sujeito que aprende está implicado em seus processos de aprender, de que ele existe na sua humanidade e complexidade, e, ainda, de que a aprendizagem se dá em uma escala de vida. Nela, os caminhos trilhados para se chegar até aquele ponto, os modos de caminhar, os descaminhos, as encruzilhadas, as trilhas futuras, os projetos de si, constituem-se em peças que podem se articular no tabuleiro da vida, em que aprender é, sobretudo, como afirma Josso (2004), aprender consigo a aprender; e, como afirma Pineau (1999), aprender é viver e viver é aprender. Aprende-se, assim, na interface eu/outros e no jogo de sentidos individual e social, nas relações intersubjetivas, nas transações consigo e com os outros, de modo que a aprendizagem é sempre uma construção de natureza subjetiva e social.

Sendo assim, reafirmamos a importância das histórias de vida como metodologia de pesquisa-formação e acentuando seu caráter incomum nos programas oficiais de formação. É comum, e até esperado, que nós formadores de professores gastemos tempo e nos ocupemos intelectualmente de pesquisas e estudos sobre a profissão docente, sob a ótica das competências e das habilidades que os educadores precisam desenvolver: o que o professor precisa saber, fazer e ser no seu trabalho. Nesta pesquisa, realizada em colaboração com as professoras de Língua Portuguesa, no âmbito de um projeto mais amplo, com vinculação a pesquisa Ruralidades diver- 
sas - Diversa ruralidades, buscamos apreender suas representações sobre vida e profissão, sobre tempo e trabalho. Esse foi um estudo de deslocamentos, de viagens, porque saindo dos nossos lugares de origem para transcendê-los, na perspectiva de partilharmos com professoras nos anos inicias da carreira, convidadas a ensinar a academia sobre a docência na zona rural, sobre como aprendem e vivem mulheres-professoras, filhas da região da Chapada Diamantina.

\section{Referências}

ALMEIDA, J. S. Mulher e Educação: a paixão pelo possível. São Paulo: Editora UNESP, 1998.

ARROYO, Miguel G. Imagens quebradas trajetórias e tempos de alunos e mestres. Petrópolis: Vozes, 2004.

BUENO, Belmira Oliveira; CATANI, Denici Bárbara; SOUSA, Cynthia Pereira de (Orgs.). A Vida e o Ofício dos Professores: formação contínua, autobiografia e pesquisa em colaboração. 4. ed. São Paulo: Escrituras, 2003.

BUENO, Belmira Oliveira; CHAMLIAN, Helena Coharik; SOUSA, Cynthia Pereira de; CATANI, Denice Barbara. Histórias de vida e autobiografias na formação de professores e profissão docente (Brasil, 1985-2003). Educação e Pesquisa, v. 32, n. 2, p. 385-410, 2006.

CANÁRIO, Rui. A escola tem futuro? Das promessas às incertezas. Porto Alegre: Artmed, 2006.

CATANI, Denice Bárbara; BUENO, Belmira A. Oliveira; SOUSA, Cynthia P. de. "O amor dos começos": por uma história das relações com a escola. Cadernos de Pesquisa, São Paulo, n. 111, p. 151-171, dez. 2000.

CATANI, Denice; BUENO, Belmira; SOUSA, Cynthia; SOUZA, M. Docência, Memória e Gênero estudos sobre formação. 4. ed. São Paulo: Escrituras, 2003. 
CATANI, Denice. Práticas de Formação e ofício docente. In: BUENO, Belmira Oliveira; CATANI, Denici Bárbara; SOUSA, Cynthia Pereira de (Orgs.). A Vida e o Ofício dos Professores: formação contínua, autobiografia e pesquisa em colaboração. 4. ed. São Paulo: Escrituras, 2003.

DELORY-MOMBERGER, C. Formação e socialização: os ateliês biográficos de projeto. Educação e Pesquisa, São Paulo, v. 32, n. 2, p. 359-371, maio/ago. 2006.

DIAS, R.; LOPES, A. Competências na formação do professor: o que (não) há de novo. Educação e Sociedade, v. 24, n. 85, p. 1155-1177, 2003. Disponível em: <www.cedes.unicamp.br $>$.

FANFANI, Emílio tente. La condición docente. Análises comparado de la Argentina, Brasil, Peru e Uruguay. 1. ed. 1. reim. Buenos Aires: Siglo XXI, 2007.

FONTANA, R. A. Como nos tornamos professoras? 3. ed. Belo Horizonte: Autêntica, 2005.

GOODSON, I. Dar voz ao professor: as histórias de vida dos professores e o seu desenvolvimento profissional. In: NÓVOA, Antonio (Org.). Vidas de Professores. 2. ed. Portugal: Porto, 2000. p. 63-78.

GUEDES-PINTO, Ana Lúcia; FONTANA, Roseli A. C. As mulheres professoras, as meninas leitoras e o menino leitor: a iniciação no universo da escrita no patriarcalismo rural brasileiro. uma leitura a partir de infância de Graciliano Ramos. Cadernos Cedes, Campinas, v. 24, n. 63, p. 165-191, maio/ago. 2004.

JESUS, Regina de Fátima de. Sobre alguns caminhos trilhados... ou mares navegados... Hoje sou professora. In: VASCONCELOS, G. A. N. Como me fiz professora. 2. ed. Rio de Janeiro: DP\&A, 2003. p. 21-41.

JOSSO, Marie-Chistine. Experiências de Vida e Formação. Prefácio Antonio Nóvoa; tradução José Claudino e Júlia Ferreira. São Paulo: Cortez, 2004. 
LAWN, Martin. Os professores e a fabricação de identidades. In: NÓVOA, A.; SCHRIEWER, J. (Orgs.). A difusão mundial da escola. Lisboa: Educa, 2000. p. 69-84.

LIBÂNEO, José C. Democratização da Escola Pública: a Pedagogia Crítico Social dos Conteúdos. 15. ed. São Paulo: Loiola, 1985.

Organização e gestão escolar: teoria e prática. Goiânia: Editora Alternativa, 2004.

LOPES, Amélia. Mal-estar na docência? Visões, razões e soluções. Cadernos CRIAP: Centros de Recurso de Informação e Apoio Pedagógico ASA Editores II, S.A. Porto: Portugal, 2001.

MEIRELES, C. Olhinhos de Gato. 3. ed. São Paulo: Moderna, 1983.

NONO, M. A.; MIZUKAMI, M. G. Processos de formação de professores iniciantes. Revista brasileira de Estudos Pedagógicos, Brasília, v. 87, n. 217, p. 382-400, set./dez. 2006.

NOVOA, Antonio. A imagem no infinito: a lenta acomodação da profissão docente a uma identidade feminina. Tradução original em francês: Paula Perin Vicentini. Texto apresentado na Faculdade de Educação da USP em 25 de novembro de 1996. 15 p.

NOVOA, Antonio. Formação de Professores e profissão docente. In: Os Professores e sua formação. 3. ed. Lisboa: Nova Enciclopédia, 1997. p. 13-33. out. 2003.

Entrevista. Revista Pátio, São Paulo, ano 7, n. 27, p. 25-28, ago./

PEREIRA, Iraci do Nascimento. O magistério: um encontro. In: BUENO, Belmira Oliveira; CATANI, Denici Bárbara; SOUSA, Cynthia Pereira de (Orgs.). A Vida e o Ofício dos Professores: formação contínua, autobiografia e pesquisa em colaboração. 4. ed. São Paulo: Escrituras, 2003.

PINEAU, G. A autoformação no decurso da vida: entre a hetero e ecoformação. In: NÓVOA, Antônio; FINGER, Mathias. O método 
(auto)biográfico e a formação. Lisboa: MR/DRHS/CFAP, 1988. p. 6376 .

PINEAU, G. Experiências de aprendizagem e Histórias de vida. In: CARRÉ, P.; GASPAR, P. Tratado das Ciências e das Técnicas de Formação. Porto Alegre: Instituto Piaget, 1999. p. 327-348. (Col. Horizontes Pedagógicos).

SÁ, M. R. G. de. O acompanhamento dos percursos de formação de professores que estudam. Caderno temático professores que estudam: uma experiência no ensino Superior. Publicação CEAP Centro de Estudos e Assessoria pedagógica. Ano II. no 2. julho, 2006.

SOARES, L.; GALVÃO, A. M. de O. Uma história de alfabetização de adultos no Brasil. In: STEPHANOU, M.; BASTOS, M. H. C. (Orgs.). Histórias e Memórias da Educação no Brasil. Vol. III - Século XX. Editora Vozes: 2005. p. 257-277.

SOUZA, Elizeu Clementino de. O conhecimento de si Estágio e narrativas de formação de professores. Rio de Janeiro: DP\&A; Salvador: UNEB, 2006.

SOUZA, Elizeu Clementino de; SOUSA, Cynthia Pereira de; CATANI, Denice Barbara. A pesquisa (auto)biográfica e a invenção de si no Brasil. Revista da FAEEBA - Educação e Contemporaneidade, Salvador, v. 17, n. 29, p. 1-11, jan./jun. 2008.

STEPHANOU, M.; BASTOS, M. H. C. (Orgs.). Histórias e Memórias da Educação no Brasil. Vol. III - Século XX. Editora Vozes: 2005.

WARSCHAUER, Cecília. Rodas em Rede Oportunidades formativas na escola e fora dela. Rio de Janeiro: Paz e Terra, 2001.

ZABALZA, MIGUEL. Diários de Aula: um instrumento de pesquisa e desenvolvimento profissional. Tradução Ernani Rosa. Porto Alegre: Artmed, 2004.

ZARAGOZA, José Manuel Esteve. O Mal-estar docente a sala de aula e a saúde dos professores. Tradução Durley de Carvalho Cavicchia. Bauru: EDUSC, 1999. 


\section{Notas}

* Doutoranda do Programa de Pós-graduação em Educação e Contemporaneidade, da Universidade do Estado da Bahia. Pesquisadora do Grupo de Pesquisa (Auto)biografia, Formação e História Oral. Bolsista Capes. E-mail: <neurilene. martins@superig.com.br>.

** Pesquisador CNPq, pós-doutor pela Universidade de São Paulo. Doutor em Educação (UFBA), com Doutorado Sanduíche na Universidade de Lisboa, Portugal. Professor titular da Universidade do Estado da Bahia (UNEB), secretário geral ANPEd (2011/2013), coordenador da Pesquisa Ruralidades diversas - Diversas ruralidades (FAPESB; CNPq). Avenida Silveira Martins, n. 2555, Cabula, CEP 41195-001, Salvador (BA). E-mail: <esclementino@uol.com.br>.

${ }^{1}$ Dados sobre a docência na América Latina e suas problemáticas podem ser encontrados nas investigações realizados por Fanfani (2007), sobre as condições da docência em um estudo comparativo realizado com docentes da zona urbana de quatro países: Argentina, Brasil, Peru e Uruguai. Para tanto, o autor trabalha com as seguintes categorias: características sociodemográficas dos docentes e 0 lugar que ocupam na estrutura social, suas relações com o trabalho, seus valores e opiniões a respeito de dimensões relevantes das políticas educativas, suas posições a respeito de valores sociais relevantes e seus consumos culturais.

${ }^{2} \mathrm{O}$ conceito de contramemória é tematizado por Catani et al. (2003) e Souza (2006) nas pesquisas sobre formação docente, como possibilidade de desconstrução de visões desqualificadas da profissão, ideologicamente construídas, aportadas e disseminadas pela memória oficial.

${ }^{3}$ Imagens como jardineiras, artífices, bordadeiras são retomadas por Arroyo (2004), para ilustrar representações e sentidos clássicos do Magistério.4 ]

${ }^{4} \mathrm{O}$ presente texto vincula-se a pesquisa 'Ruralidades diversas - Diversas ruralidades' (FAPESB; CNPq) e sistematiza resultados da pesquisa 'Histórias de Vida de professoras de Língua Portuguesa da Chapada Diamantina nos anos iniciais da carreira?.

${ }^{5}$ Colaboraram nesse estudo as professoras Adriana Brandão, Adriana Sousa, Aparecida de Oliveira, Cleide Novaes, Edna Lima, Eliane Araújo, Elizete Santos, Josemary Neves, Júlia Neta, Luana Serra, Lucilene Santos, Luciana Oliveira, Maiara Macedo, Maria Selene da Silva, Raquel de Oliveira e Rosane de Oliveira, autorizado com carta de cessão para utilização dos seus respectivos nomes.

${ }^{6}$ Sobre o direito à formação continuada e seus desdobramentos na escola, consultar o capítulo XI, "Formação continuada", da obra de Libâneo (2004), e o capítulo 2, "Escola, aprendizagem e inovação", do livro de Canário (2006).

${ }^{7}$ A maioria das professoras colaboradoras da pesquisa ingressou na docência de Língua Portuguesa após a conclusão do curso de Magistério do Ensino Médio. Com a proliferação dos cursos de graduação à distância, principalmente, progressivamente todas ingressaram no ensino superior, encontrando-se com essa formação em curso no tempo da pesquisa. Do conjunto de dezesseis professoras, nove estão cursando a licenciatura de letras, sendo que quatro dessas em curso presencial na UNEB. 
${ }^{8}$ Essa é uma das professoras integrantes do grupo de pesquisa e formação, realizado na FEUSP, por Catani e Bueno, experiência registrada no livro $A$ vida e o ofício de professores (BUENO et al., 2003).

${ }^{9}$ A pesquisadora tomou como objeto de estudo as memórias da profissão docente de seis professoras que permanecem na escola pública, a despeito da precariedade das condições de trabalho, na dissertação de Mestrado "Professoras da Escola Pública - Por que ficam: uma História a contar".

${ }^{10}$ Nos estudos realizados por Fonseca (2003) sobre como alguém se torna professor(a) de história, localizamos condição semelhante à das professoras de Língua Portuguesa, quando os professores, além da disciplina História, lecionam outras a exemplo de OSPB, Geografia e EMC.

${ }^{11}$ Dos 84 professores mapeados na primeira fase da pesquisa, 13 têm licenciatura em Letras, 24 estão cursando essa licenciatura, vinte possuem a formação em Magistério no ensino médio e os demais ou são estudantes de outras licenciaturas ou já tem nível superior em outros cursos.

${ }^{12}$ Segundo os estudos de Zaragoza (1999), os salários são uma das variáveis que definem a permanência ou não do professor na profissão.

${ }^{13}$ Em julho de 2008, participamos do Seminário Educação e Convivência no Campo: avanços e desafios para o semiárido, realizado pelo Governo Estadual e o Unicef, em que pudemos aproximar do estado da arte das escolas rurais dessa região, contexto no qual ouvi depoimentos sobre as condições de funcionamento dos anexos de escolas da sede, que funcionam na zona rural, em algumas cidades nordestinas.

${ }^{14} \mathrm{O}$ mal-estar docente é abordado na literatura atual como um fenômeno mundial que emerge da crise da profissão docente, das situações problemáticas a que se expõe o professor na sala de aula, dentro e fora da escola. Essa questão é aprofundada nos estudos de Zaragoza (1999) e de Lopes (2001).

${ }^{15}$ Não trataremos aqui de aspectos concernentes aos trabalhos domésticos e assistência à família, função que as mulheres geralmente conjugam com a profissão, não por ser aspecto menor, mas tendo em vista a temática focalizada na pesquisa.

${ }^{16}$ Somam-se a tais deslocamentos outros concernentes aos percursos sede/zona rural, seja para aquelas que moram na sede, seja para aquelas que moram na zona rural. 